\title{
Numerical Simulation for the Soil-Pile-Structure Interaction under Seismic Loading
}

\author{
Lifeng Luan, ${ }^{1}$ Yunbin Liu, ${ }^{2}$ and Ying $\mathrm{Li}^{3}$ \\ ${ }^{1}$ School of Earth Sciences and Resources, China University of Geosciences, Beijing 100083, China \\ ${ }^{2}$ Weihai Bohai Sea Group Co., Ltd., Weihai 264200, China \\ ${ }^{3}$ Institute of Mineral Resources, Chinese Academy of Geological Sciences, Beijing 100037, China
}

Correspondence should be addressed to Ying Li; liyingacgs@126.com

Received 4 June 2015; Revised 15 July 2015; Accepted 5 August 2015

Academic Editor: Roberto Fedele

Copyright (C) 2015 Lifeng Luan et al. This is an open access article distributed under the Creative Commons Attribution License, which permits unrestricted use, distribution, and reproduction in any medium, provided the original work is properly cited.

\begin{abstract}
Piles are widely used as reinforcement structures in geotechnical engineering designs. If the settlement of the soil is greater than the pile, the pile is pulled down by the soil, and negative friction force is produced. Previous studies have mainly focused on the interaction of pile-soil under static condition. However, many pile projects are located in earthquake-prone areas, which indicate the importance of determining the response of the pile-soil structure under seismic load. In this paper, the nonlinear, explicit, and finite difference program FLAC3D, which considers the mechanical behavior of soil-pile interaction, is used to establish an underconsolidated soil-pile mode. The response processes of the pile side friction force, the pile axial force, and the soil response under seismic load are also analyzed.
\end{abstract}

\section{Introduction}

Pile foundation is widely used in geotechnical design as a reinforcing structure [1-3]. If the pile is driven into consolidated soil and the settlement of the pile is greater than that of the soil, the pile is supported by the soil, and positive friction force is produced. If the settlement of the soil is greater than that of the pile, the pile is pulled down by the soil, and negative friction force is produced. Given the pulling effect of soil, the negative friction force on the pile side will reduce its carrying capacity, causing engineering instability [4]. Therefore, the mechanism of a pile in underconsolidated soil and the distribution of the positive and negative friction forces should be examined considering its significance in engineering design. Theoretical analysis, as well as laboratory and in situ experimental methods, had been used by several studies to establish interactional models of pile and soil [4-6]. Qualitative experimental results have been obtained [7-10]. These previous studies have mainly analyzed the pile-soil response under static force, but pile engineering can be located in an earthquake-prone area. Thus, examining the response of pile-soil structure under seismic load is important; Tabatabaiefar et al. [11] depicted different effects on the seismic response of moment-resisting building frames and lateral seismic response of building frames considering dynamic soil-structure interaction effects [12]. At present, FLAC3D, a nonlinear explicit finite difference program that considers the mechanical behavior of soil-pile interaction, has been widely used in geotechnical engineering [13-15]. Cai [16] applied FLAC and Phase 2 to analyze tunnel excavation problems. Hakami [17] used FLAC and FLAC3D to simulate a comprehensive pump test at Sellafield and predict the hydromechanical consequences of the sinking of a shaft. In the current study, we used the numerical software FLAC3D to establish an underconsolidated, soil-pile model and analyze the response processes of the pile side friction force, pile axial force, and soil under seismic load. The results are expected to provide further insight into the underlying pile-soil interaction mechanism and the load transferring law of pile. 
TABLE 1: Calculation parameters.

\begin{tabular}{lccccccc}
\hline Material & $t / \mathrm{m}$ & $\gamma / \mathrm{kN} / \mathrm{m}^{3}$ & $E / \mathrm{MPa}$ & $\mu$ & $c / \mathrm{kPa}$ & $\phi /^{\circ}$ & Shear wave velocity $/ \mathrm{m} / \mathrm{s}$ \\
\hline Underconsolidated soil & 4 & 19.0 & 13.5 & 0.42 & 25.0 & 15.5 & 130.0 \\
Consolidated soil & 16 & 19.3 & 30.0 & 0.39 & 30.0 & 19.0 & 200.0 \\
\hline
\end{tabular}

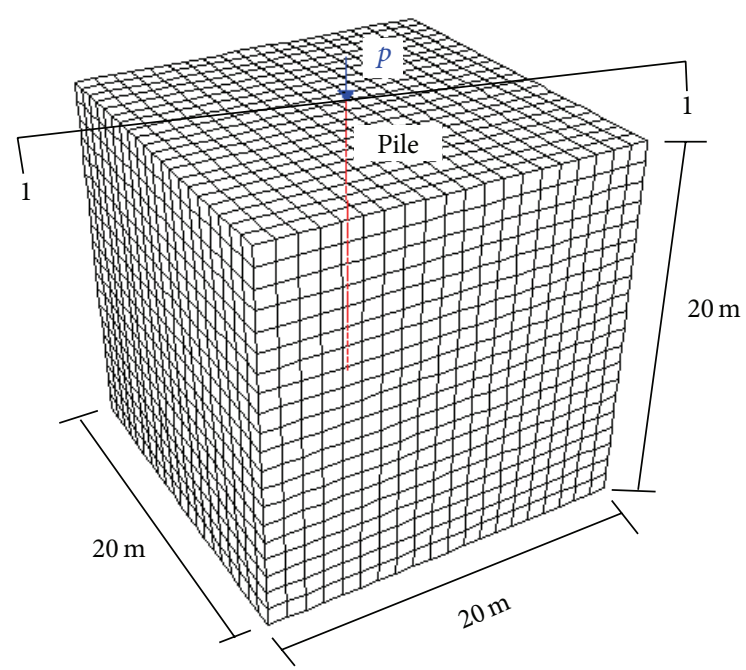

FIgURE 1: Numerical calculation model.

\section{Modeling}

2.1. Numerical Modeling. FLAC3D is used to establish the $20 \mathrm{~m} \times 20 \mathrm{~m} \times 20 \mathrm{~m}$ numerical model, with $4 \mathrm{~m}$ underconsolidated soil at the upper part and $16 \mathrm{~m}$ consolidated soil at the lower part (Figure 1). The pile is simulated by the pile element [18] in the FLAC3D and set at the center of the model. During the interaction of pile and soil, the pile bears the axial pressure, axial friction force, and transverse shear. The pile is divided into microsegments of equal length, which were used in the elastic-plastic analysis. Finally, the stress-strain response of the whole pile is obtained by the integral accumulation effect. Piles interact with the soil via shear and normal coupling springs. The coupling springs are nonlinear, spring-slider connectors that transfer forces and motion between the pile and the grid at the pile nodes (by way of the link emanating from each pile node). The normal and shear behavior of the pile-grid interface is cohesive and frictional in nature. The behavior of the normal coupling springs includes the ability to model load reversal and the formation of a gap between the pile and the grid. The normal coupling springs can simulate the effect of the host medium squeezing around the pile. The shear behavior of the grout annulus, during relative shear displacement between the pile/grout interface and the grout/soil interface, is described numerically by stiffness, cohesive strength, friction angle, and exposed perimeter. The equivalent linear dynamic behavior of soil-pile interaction during earthquake has been used, as indicated in Fatahi and Tabatabaiefar [19] work.

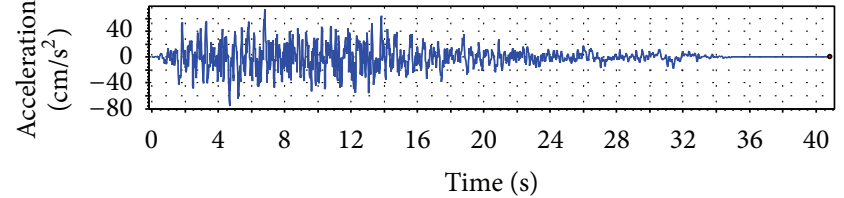

FIgURE 2: Acceleration time history curve.

The Mohr-Coulomb ideal elastic-plastic model is used to describe the stress and strain of the soil [20-22]. In the calculation, the load is the gravity stress field, and the physical and mechanical parameters are shown in Table 1 , where $t$, $\gamma, E$, and $c$ are the thickness, volume, elastic modulus, and cohesion of soil. Poisson's ratio is denoted by $\mu$, and $\phi$ is the internal friction force angle. The parameters of the pile are as follows: diameter, $0.8 \mathrm{~m}$; length, $15.0 \mathrm{~m}$; elastic modulus, 25.0 GPa; Poisson's ratio, 0.2 ; and volume weight, $24.0 \mathrm{kN} / \mathrm{m}^{3}$. The model has two boundary conditions, namely, static and dynamic, in which the static boundary is set at normal displacement constraint on the bottom and sides. At the beginning of the dynamic calculation under the dynamic boundary condition with the free field boundary condition, the static constraint is removed, and a dynamic viscous boundary is applied to absorb the seismic waves. Meanwhile, a dynamic absorbing boundary is applied to the bottom of the model [23].

2.2. The Seismic Load. The seismic waves are applied at the bottom of the model. According to the probability of exceeding $10 \%$ of the time history of the acceleration of the bed rock (Figure 2) in 50 years [24], the velocity-time history curve (Figure 3 ) is obtained by the acceleration of time history curve. Then, subsequently, FLAC3D reads the velocity-time history curve (Figure 4) to apply the dynamic load at the bottom of the model. From the seismic safety evaluation report for the tested site in Changsha Hunan Province of China, the damping rate is considered as 0.05 . Similar seismic waves are inputted on both $x$ - and $y$-directions. The peak acceleration of the seismic waves on the $z$-direction is set to two-thirds of that in the horizontal direction, and the duration of the calculated seismic waves is $6 \mathrm{~s}$.

\section{Calculations and Analysis}

For the numerical calculation, we first establish the part under the soil and then obtain the system of the equilibrium state by calculation. Afterward, the upper part of the soil, consolidated soil, and pile are placed at the center of the model. Finally, the response of the soil deformations, distribution of 


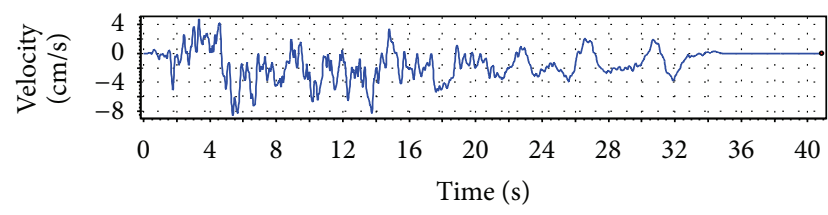

Figure 3: Velocity-time curve.

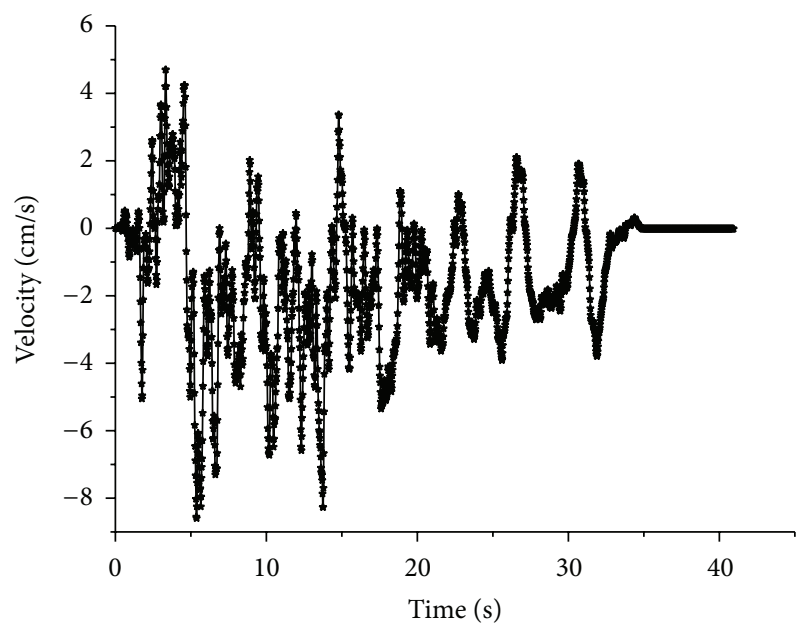

FIGURE 4: Velocity-time curve in FLAC3D.

the pile side friction force, and axial force are analyzed under the seismic load. A $200 \mathrm{kN}$ load (approximately $10 \%$ of axial bearing capacity of the pile) is set at the top of pile.

3.1. Distribution of Friction Force. Figure 5 shows the pile side friction force, which varies over time. The distribution and the values of the negative and positive pile side friction forces change over the seismic duration. Small differences are found between the forces in the model and those of the pile without the influence of an earthquake. The neutral point is the position at which the pile side friction force changes from positive to negative. The variation of the location of the neutral point is small over the seismic duration. This condition is due to the fact that although the corresponding displacement of pile and soil occurs under the dynamic forces, the relative displacement of pile and soil is small. Figure 6 shows the distribution of the corresponding pile side friction force. From the top to the bottom of pile, the algebraic value of the friction force is increasing, and the upper part of pile bears the negative friction force, which gradually transforms into positive friction force along the pile. The maximum value of the positive friction force is obtained at the bottom of the pile. The distributions of friction force with and without seismic load are the same, but their values vary over the seismic duration.

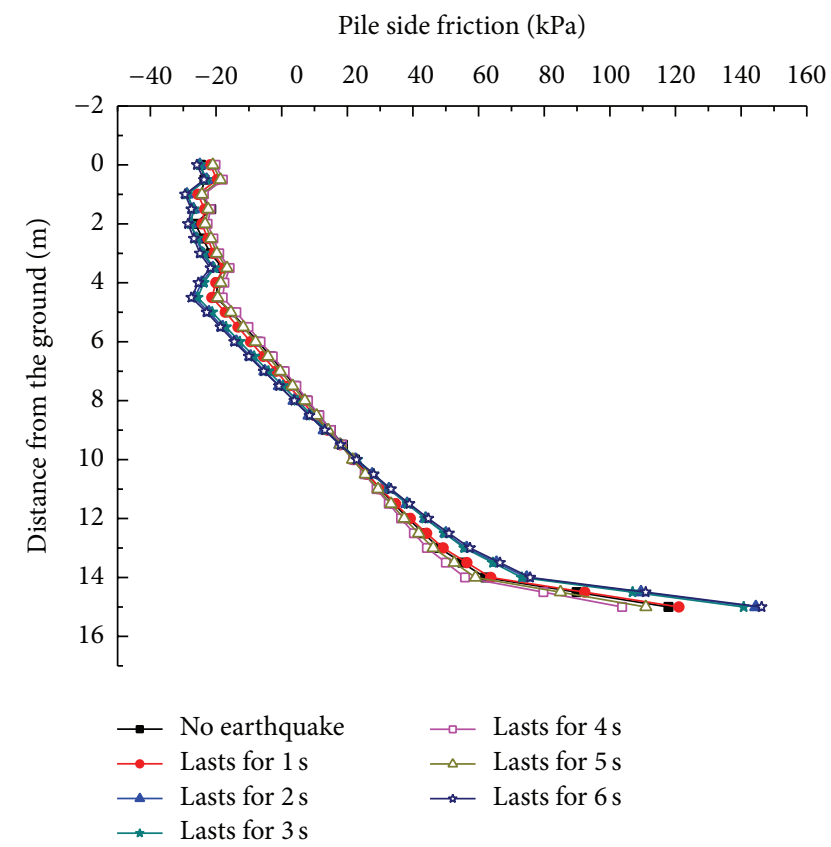

FIGURE 5: Pile side friction force variations with time.

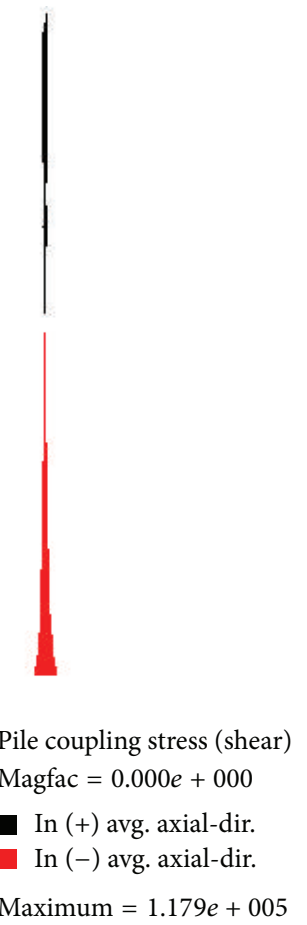

FIgURE 6: Pile side friction force along the pile.

3.2. Distribution of Axial Force. Figure 7 shows the variation in the pile axial force over time. From the top to the bottom of the pile, the axial force of pile initially increases and subsequently decreases along the pile shaft. In addition, the maximum value is obtained at the neutral point, at which the friction force is 0 . Above the neutral point, the pile bears 


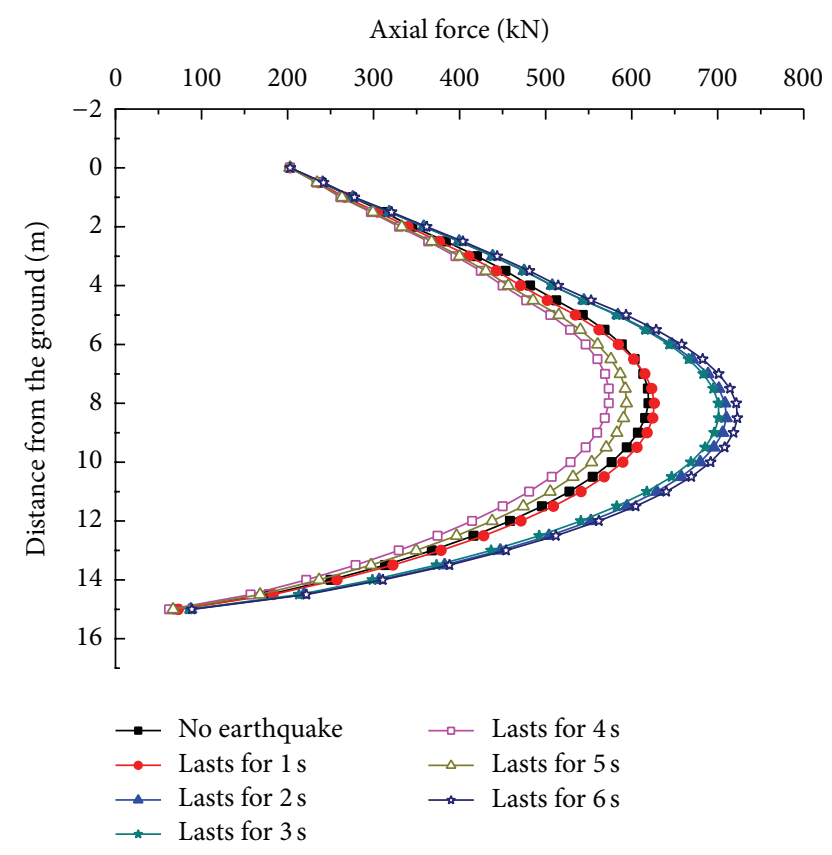

FIGURE 7: Pile axial force over time.

the negative friction force, and the axial force is the sum of its own weight and the negative friction force. Therefore, the axial force increases from the top of the pile to the neutral point. Below the neutral point, the pile bears the positive friction force, and the axial force is the difference of its weight and the positive friction force. Therefore, the axial force decreases gradually along the pile. In an earthquake, the axial force of pile also changes over the longitudinal waves in the seismic waves. Comparing these results with the axial force of pile without seismic load, the axial force is reciprocating around. For the particles of the rock and soil bearing the reciprocating action of the seismic waves, the axial force reaches its maximum value when the seismic duration earthquake lasts for 2, 3, and $6 \mathrm{~s}$. The corresponding axial force is shown in Figure 8, which shows that the whole pile is under compressive stress, and its value increases at the beginning and then decreases from the top to the bottom of the pile. Moreover, the axial force changes over the reciprocation of the seismic waves under different seismic durations (Figure 7).

3.3. Displacement Contours of the Soil around Pile. Figure 9 shows the numerical displacement contour of the soil around pile, in which the negative value indicates the downward direction of the displacement. Considering the impact of the pile side friction force, the soil is propped up and down by the pile. However, given the effect of seismic loads, especially the longitudinal waves, the settlement of soil changes significantly, but the variation rule is not monotonous. The compression and stretching effects on the soil occur alternately when the longitudinal waves pass. Consequently, the soil settlement increases and decreases alternately. The settlement reaches its maximum value of $5.13 \mathrm{~cm}$ when the seismic duration is $6 \mathrm{~s}$.

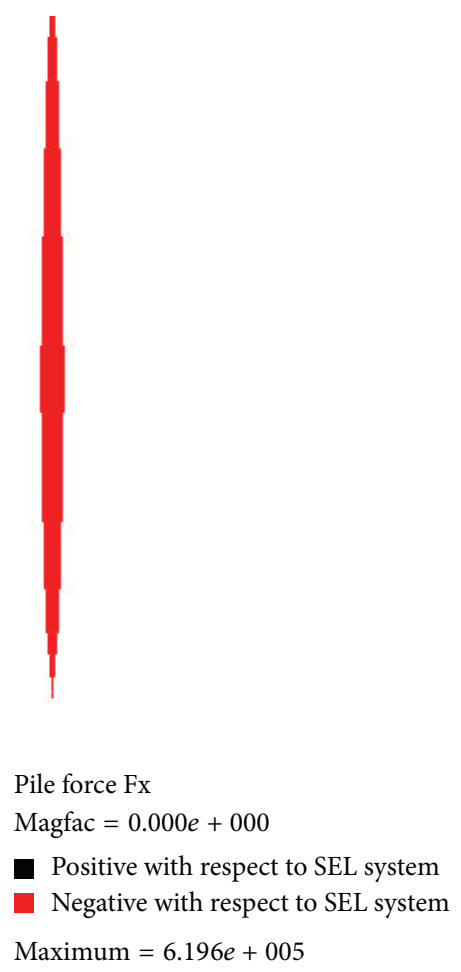

FIGURE 8: Distribution of the pile axial force.

A comparison of the horizontal displacement contours of the soil around pile with and without seismic loads (Figure 10) shows that the horizontal displacement of the soil around pile does not occur without an earthquake. However, when an earthquake occurs, the horizontal displacement becomes obvious. During the earthquake, the reciprocating variation of the horizontal displacement will occur. The effect of the seismic load on the horizontal shear action of soil becomes evident, and the maximum horizontal displacement of the surface soil is $4.18 \mathrm{~cm}$, which occurs when the seismic duration is $5 \mathrm{~s}$.

Figure 11 further shows the $3 \mathrm{D}$ effect of the numerical displacement contour of soil. Considering the pile side friction force, the weight of soil, and the seismic effect, a certain amount of settlement occurs, and the maximum vertical displacement is $5.13 \mathrm{~cm}$, which occurs when the seismic duration is $6 \mathrm{~s}$. The settlement of the soil around pile varies with varying seismic durations, and the variation rule is not monotonous. Instead, the value changes with the reciprocating movement of the seismic waves.

\section{Conclusions}

(1) Under the seismic dynamic loads, the distributions of the negative and positive pile side friction forces vary over the seismic duration. Differences between the pile side friction forces with and without earthquake are obtained. In addition, during the earthquake, the neutral point of pile changes a little. 
Contour of $Z$-displacement Plane: on

Magfac $=0.000 e+000$
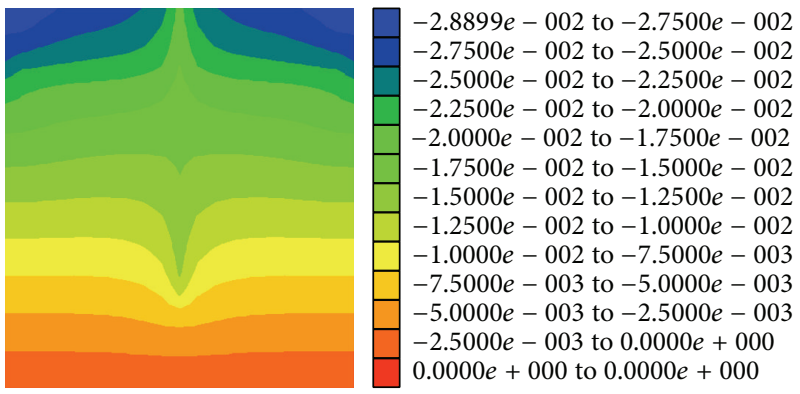

(a) Without dynamic force
Contour of Z-displacement

Plane: on

Magfac $=0.000 e+000$

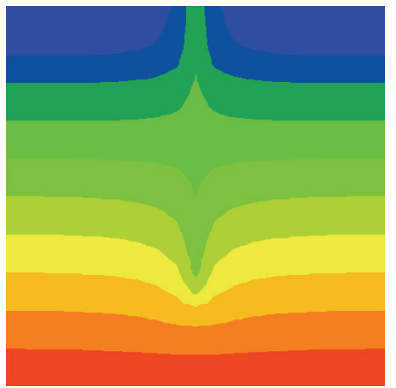

\begin{tabular}{|l}
$-2.4451 e-002$ to $-2.2500 e-002$ \\
$-2.2500 e-002$ to $-2.0000 e-002$ \\
$-2.0000 e-002$ to $-1.7500 e-002$ \\
$-1.7500 e-002$ to $-1.5000 e-002$ \\
$-1.5000 e-002$ to $-1.2500 e-002$ \\
$-1.2500 e-002$ to $-1.0000 e-002$ \\
$-1.0000 e-002$ to $-7.5000 e-003$ \\
$-7.5000 e-003$ to $-5.0000 e-003$ \\
$-5.0000 e-003$ to $-2.5000 e-003$ \\
$-2.5000 e-003$ to $-7.5978 e-005$
\end{tabular}

Interval $=2.5 e-003$

(b) Seismic duration of $1 \mathrm{~s}$

Contour of $Z$-displacement

Plane: on

Magfac $=0.000 e+000$

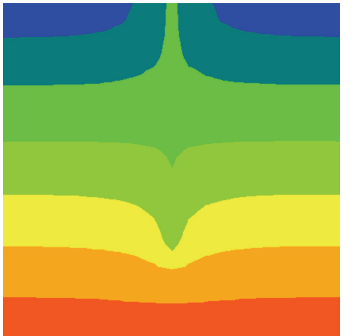

\begin{tabular}{|l}
$-5.1296 e-002$ to $-5.0000 e-002$ \\
$-5.0000 e-002$ to $-4.5000 e-002$ \\
$-4.5000 e-002$ to $-4.0000 e-002$ \\
$-4.0000 e-002$ to $-3.5000 e-002$ \\
$-3.5000 e-002$ to $-3.0000 e-002$ \\
$-3.0000 e-002$ to $-2.5000 e-002$ \\
$-2.5000 e-002$ to $-2.1106 e-002$ \\
Interval $=5.0 e-003$
\end{tabular}

(c) Seismic duration of $6 \mathrm{~s}$

FIGURE 9: Vertical displacement contour of the soil around pile under different seismic durations.

Contour of $X$-displacement

Plane: on

Magfac $=0.000 e+000$
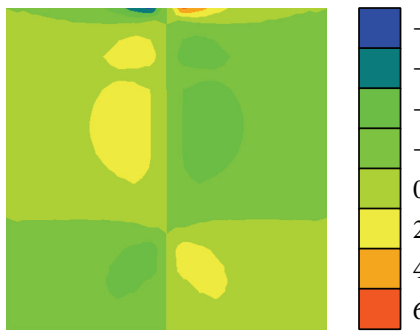

$-6.3058 e-004$ to $-6.0000 e-004$

$-6.0000 e-004$ to $-4.0000 e-004$

$-4.0000 e-004$ to $-2.0000 e-004$

$-2.0000 e-004$ to $0.0000 e+000$

$0.0000 e+000$ to $2.0000 e-004$

$2.0000 e-004$ to $4.0000 e-004$

$4.0000 e-004$ to $6.0000 e-004$

$6.0000 e-004$ to $6.3012 e-004$

Interval $=2.0 e-004$

(a) Without dynamic force

Contour of $X$-displacement

Plane: on

Magfac $=0.000 e+000$
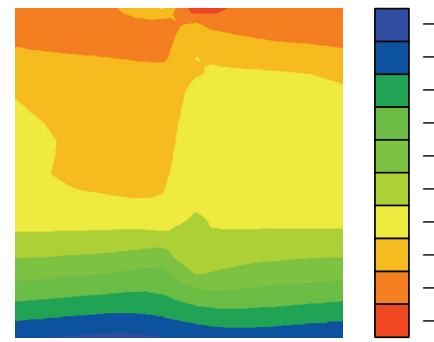

$-7.1261 e-003$ to $-7.0000 e-003$ $-7.0000 e-003$ to $-6.5000 e-003$ $-6.5000 e-003$ to $-6.0000 e-003$ $-6.0000 e-003$ to $-5.5000 e-003$ $-5.5000 e-003$ to $-5.0000 e-003$ $-5.0000 e-003$ to $-4.5000 e-003$ $-4.5000 e-003$ to $-4.0000 e-003$ $-4.0000 e-003$ to $-3.5000 e-003$ $-3.5000 e-003$ to $-3.0000 e-003$ $-3.0000 e-003$ to $-2.6596 e-003$ Interval $=5.0 e-004$

(c) Seismic duration of $3 \mathrm{~s}$
Contour of $X$-displacement Plane: on

Magfac $=0.000 e+000$

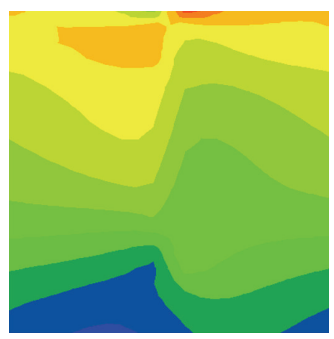

$-2.9258 e-004$ to $-2.5000 e-004$ $-2.5000 e-004$ to $0.0000 e+000$ $0.0000 e+000$ to $2.5000 e-004$ $2.5000 e-004$ to $5.0000 e-004$ $5.0000 e-004$ to $7.5000 e-004$ $7.5000 e-004$ to $1.0000 e-003$ $1.0000 e-003$ to $1.25000 e-003$ $1.2500 e-003$ to $1.5000 e-003$ $1.5000 e-003$ to $1.7500 e-003$ $1.7500 e-003$ to $2.0000 e-003$ $2.0000 e-003$ to $2.1455 e-003$

Interval $=2.5 e-004$

(b) Seismic duration of $1 \mathrm{~s}$

Contour of $X$-displacement Plane: on

Magfac $=0.000 e+000$
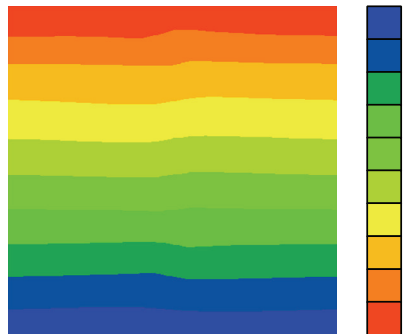

$1.8037 e-002$ to $2.0000 e-002$ $2.0000 e-002$ to $2.2500 e-002$ $2.2500 e-002$ to $2.5000 e-002$ $2.5000 e-002$ to $2.7500 e-002$ $2.7500 e-002$ to $3.0000 e-002$ $3.0000 e-002$ to $3.2500 e-002$ $3.2500 e-002$ to $3.5000 e-002$ $3.5000 e-002$ to $3.7500 e-002$ $3.7500 e-002$ to $4.0000 e-002$ $4.0000 e-002$ to $4.1768 e-002$ Interval $=2.5 e-003$

(d) Seismic duration of $5 \mathrm{~s}$

FIGURE 10: Vertical displacement contour of the soil around pile under different seismic durations. 


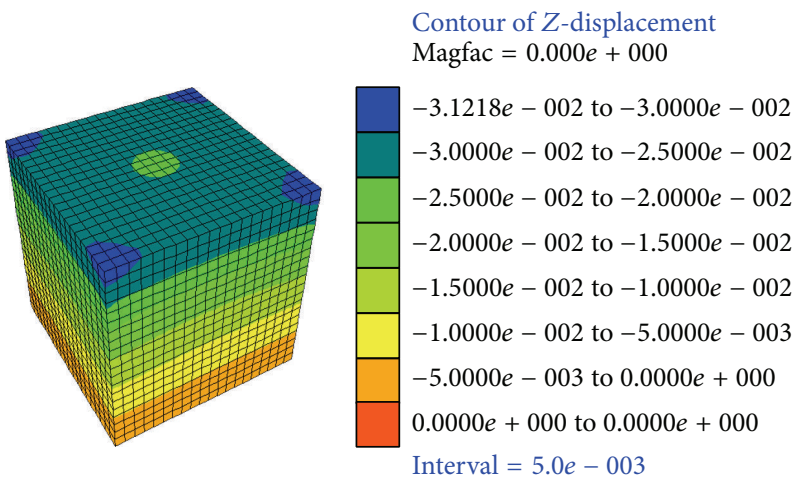

(a) Without dynamic force

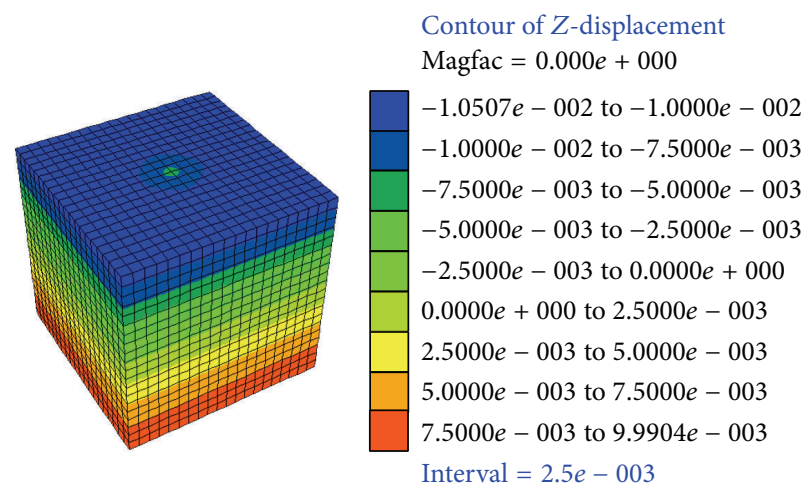

(c) Seismic duration of $3 \mathrm{~s}$

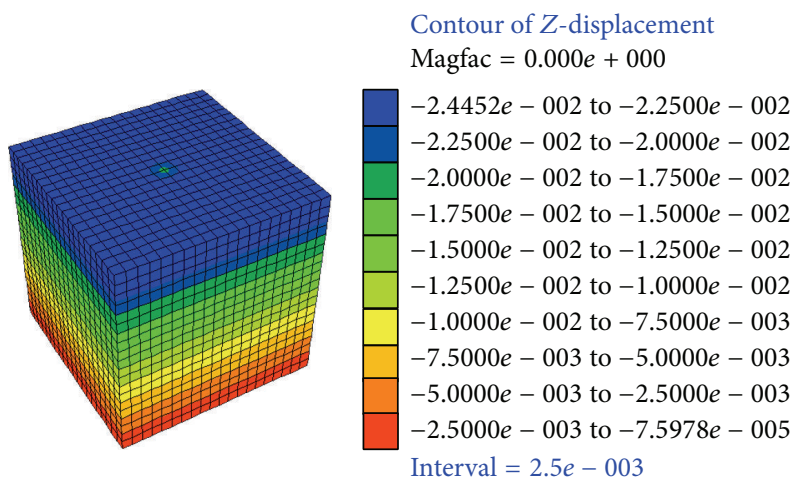

(b) Seismic duration of $1 \mathrm{~s}$

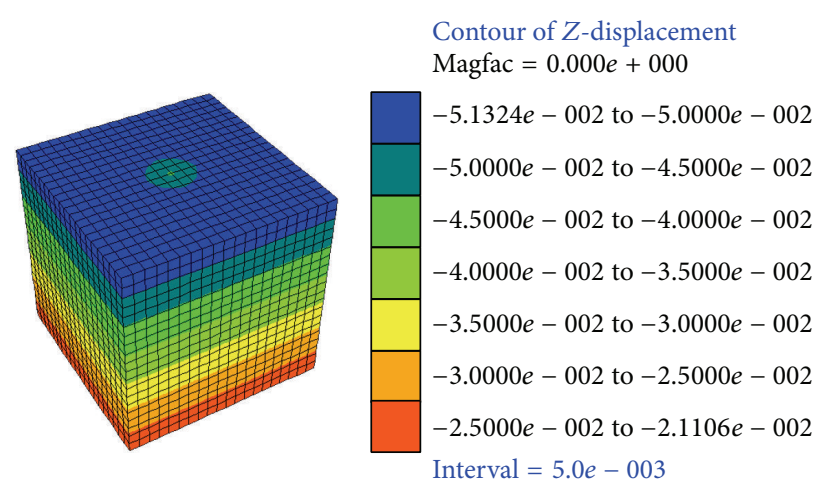

(d) Seismic duration of $5 \mathrm{~s}$

FIGURE 11: Settlement of surface soil with different seismic durations.

(2) The axial force of pile with seismic load changes over the longitudinal waves in the seismic waves. Compared with the axial force of pile without seismic load, the axial force of the pile with seismic load also changes repeatedly because the rock and soil particles bear the reciprocating action of seismic waves.

(3) The effect of seismic loads, especially the longitudinal waves, causes significant changes in the settlement of soil, but the variation rule is not monotonous. The compression and stretching effects on the soil occur alternately when the longitudinal waves pass, causing an alternating increase and decrease in the settlement of the soil.

(4) Horizontal displacement of the soil around the pile does not occur without seismic load. However, when an earthquake occurs, the horizontal displacement increases. During an earthquake, the reciprocating variation of the horizontal displacement occurs, and the effect of seismic load on the horizontal shear action of soil becomes evident.

\section{Conflict of Interests}

The authors declare that there is no conflict of interests regarding the publication of this paper.

\section{Acknowledgment}

The research project was supported by National Natural Science Foundation of China (41202057 and 51474249).

\section{References}

[1] R. Zhang, J. Zheng, H. Pu, and L. Zhang, "Analysis of excavation-induced responses of loaded pile foundations considering unloading effect," Tunnelling and Underground Space Technology, vol. 26, no. 2, pp. 320-335, 2011.

[2] B. K. Maheshwari, K. Z. Truman, M. H. El Naggar, and P. L. Gould, "Three-dimensional nonlinear analysis for seismic soilpile-structure interaction," Soil Dynamics and Earthquake Engineering, vol. 24, no. 4, pp. 343-356, 2004.

[3] K. T. Chau, C. Y. Shen, and X. Guo, "Nonlinear seismic soil-pilestructure interactions: shaking table tests and FEM analyses," Soil Dynamics and Earthquake Engineering, vol. 29, no. 2, pp. 300-310, 2009.

[4] W. Y. Shen and C. I. Teh, "A variational solution for downdrag force analysis of pile groups," International Journal of Geomechanics, vol. 2, no. 1, pp. 75-91, 2002.

[5] E. E. Alonso, A. Josa, and A. Ledesma, "Negative skin friction on piles: a simplified analysis and prediction procedure," Geotechnique, vol. 34, no. 3, pp. 341-357, 1984.

[6] H. G. Poulos and E. H. Davis, "Prediction of downdrag forces in end-bearing piles," Journal of the Geotechnical Engineering Division, vol. 101, no. 2, pp. 189-204, 1975. 
[7] M. Ashour and H. Ardalan, "Analysis of pile stabilized slopes based on soil-pile interaction," Computers and Geotechnics, vol. 39, pp. 85-97, 2012.

[8] A. S. Hokmabadi, B. Fatahi, and B. Samali, "Assessment of soilpile-structure interaction influencing seismic response of midrise buildings sitting on floating pile foundations," Computers and Geotechnics, vol. 55, pp. 172-186, 2014.

[9] F. Liang, Z. Song, and W. D. Guo, "Group interaction on vertically loaded piles in saturated poroelastic soil," Computers and Geotechnics, vol. 56, pp. 1-10, 2014.

[10] J.-F. Lu and C.-Y. He, "A model for the seismic analysis of a periodic viaduct when considering the pile-soil-structure interaction," Soil Dynamics and Earthquake Engineering, vol. 56, pp. $13-27,2014$

[11] H. R. Tabatabaiefar, B. Fatahi, and B. Samali, "Seismic behavior of building frames considering dynamic soil-structure interaction," International Journal of Geomechanics, vol. 13, no. 4, pp. 409-420, 2013.

[12] S. H. R. Tabatabaiefar, B. Fatahi, and B. Samali, "Lateral seismic response of building frames considering dynamic soil-structure interaction effects," Structural Engineering \& Mechanics, vol. 45, pp. 311-321, 2013.

[13] M. C. He, J. L. Feng, and X. M. Sun, "Stability evaluation and optimal excavated design of rock slope at Antaibao open pit coal mine, China," International Journal of Rock Mechanics and Mining Sciences, vol. 45, no. 3, pp. 289-302, 2008.

[14] M. Cai, P. K. Kaiser, H. Morioka et al., "FLAC/PFC coupled numerical simulation of $\mathrm{AE}$ in large-scale underground excavations," International Journal of Rock Mechanics and Mining Sciences, vol. 44, no. 4, pp. 550-564, 2007.

[15] H. Lin, W. Xiong, and P. Cao, "Stability of soil nailed slope using strength reduction method," European Journal of Environmental and Civil Engineering, vol. 17, no. 9, pp. 872-885, 2013.

[16] M. Cai, "Influence of stress path on tunnel excavation response-numerical tool selection and modeling strategy," Tunnelling and Underground Space Technology, vol. 23, no. 6, pp. 618-628, 2008.

[17] H. Hakami, "Rock characterisation facility (RCF) shaft sinkingnumerical computations using FLAC," International Journal of Rock Mechanics and Mining Sciences, vol. 38, no. 1, pp. 59-65, 2001.

[18] H. Lin, Z. Xiong, T. Liu, R. Cao, and P. Cao, "Numerical simulations of the effect of bolt inclination on the shear strength of rock joints," International Journal of Rock Mechanics and Mining Sciences, vol. 66, pp. 49-56, 2014.

[19] B. Fatahi and S. H. R. Tabatabaiefar, "Fully nonlinear versus equivalent linear computation method for seismic analysis of midrise buildings on soft soils," International Journal of Geomechanics, vol. 14, no. 4, Article ID 04014016, 2014.

[20] H. C. Biscaia, C. Chastre, and M. A. G. Silva, "Modelling GFRP-to-concrete joints with interface finite elements with rupture based on the Mohr-Coulomb criterion," Construction and Building Materials, vol. 47, pp. 261-273, 2013.

[21] F. Ebnoether and D. Mohr, "Predicting ductile fracture of low carbon steel sheets: stress-based versus mixed stress/strainbased Mohr-Coulomb model," International Journal of Solids and Structures, vol. 50, no. 7-8, pp. 1055-1066, 2013.

[22] H. Lin and P. Cao, "A dimensionless parameter determining slip surfaces in homogeneous slopes," KSCE Journal of Civil Engineering, vol. 18, no. 2, pp. 470-474, 2014.
[23] Itasca Consulting Group, Fast Lagrangian Analysis of Continua in 3 Dimensions, User Manual, Version 3.1, Itasca Consulting Group, Minneapolis, Minn, USA, 2004.

[24] C. Liu, S. Qi, L. Tong, and F. Zhao, "Stability analysis of slope under earthquake with FLAC3D," Chinese Journal of Rock Mechanics and Engineering, vol. 23, no. 16, pp. 2730-2733, 2004. 


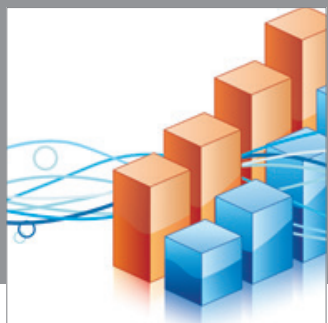

Advances in

Operations Research

mansans

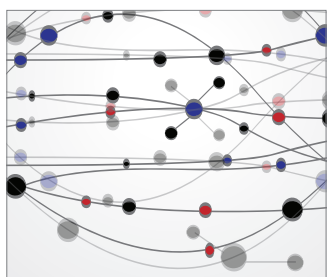

The Scientific World Journal
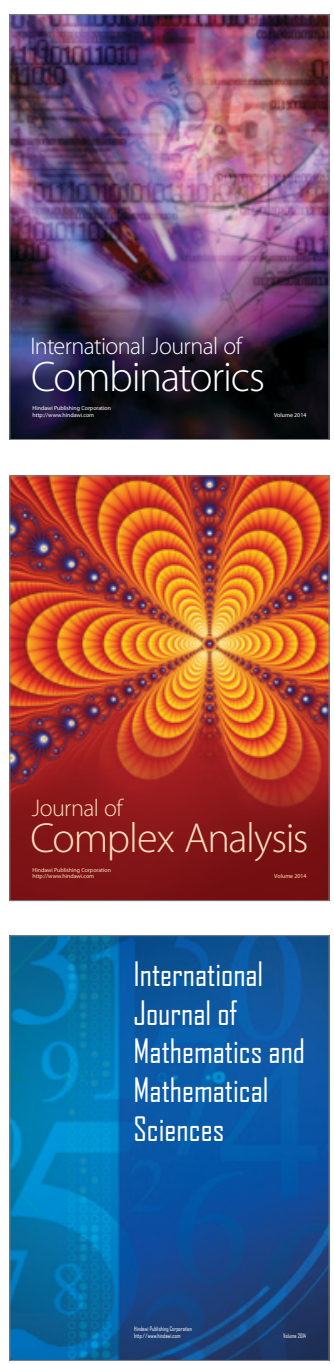
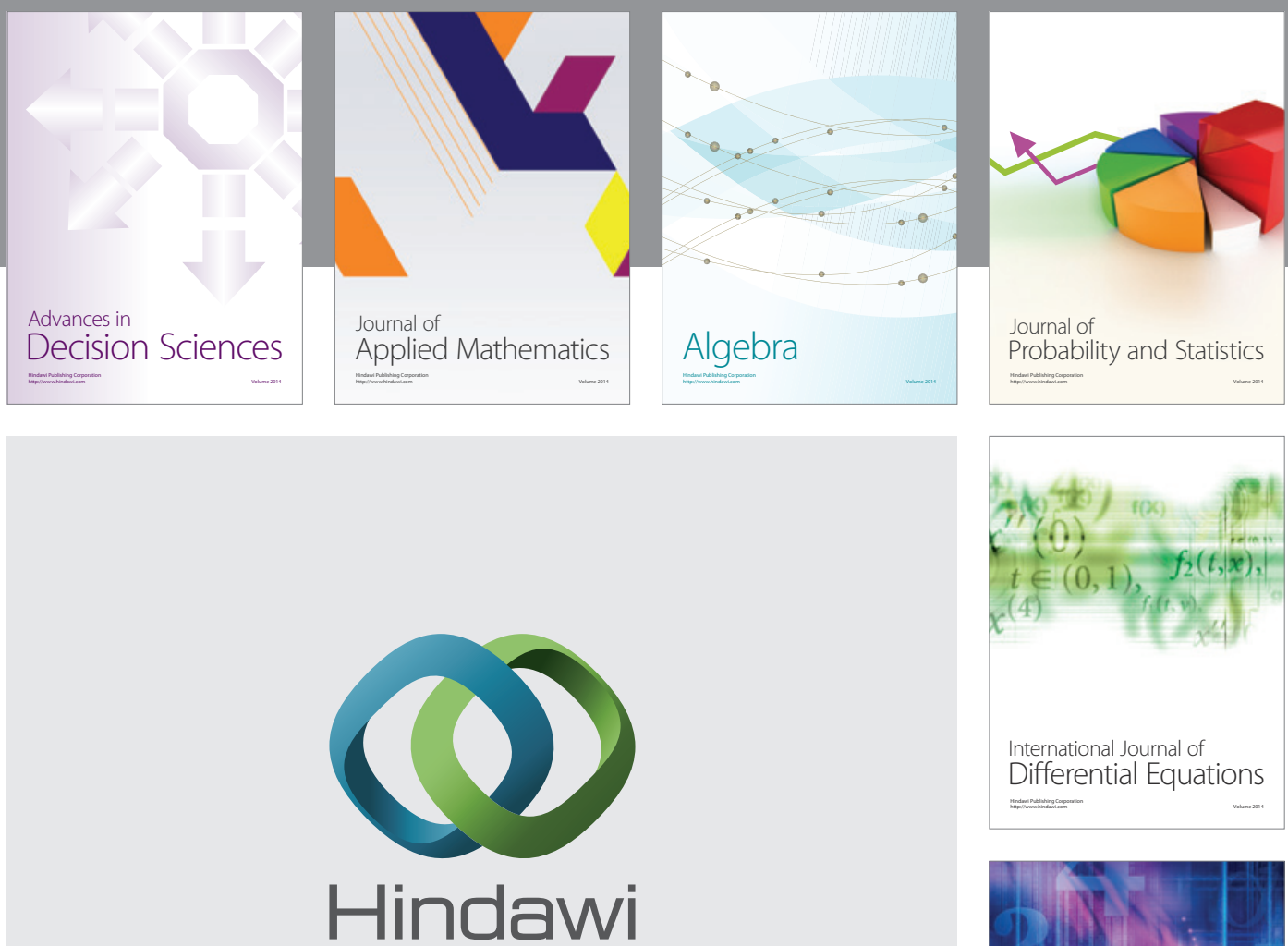

Submit your manuscripts at http://www.hindawi.com
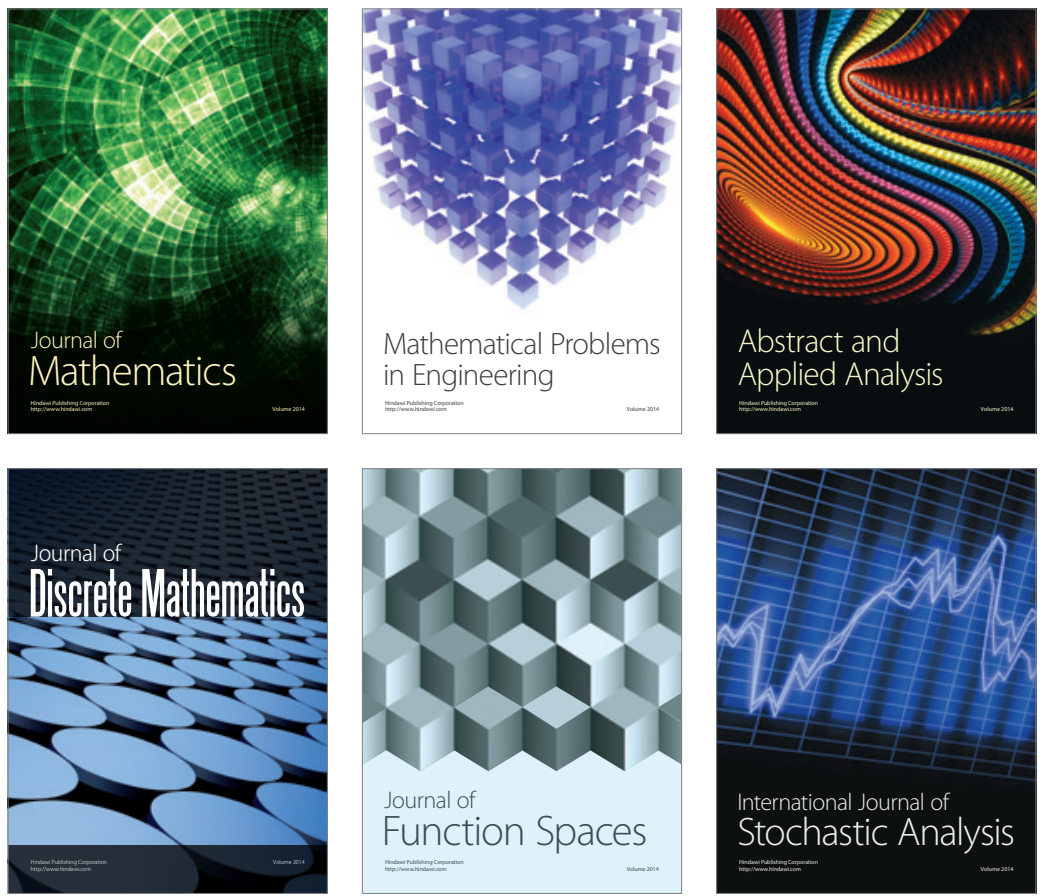

Journal of

Function Spaces

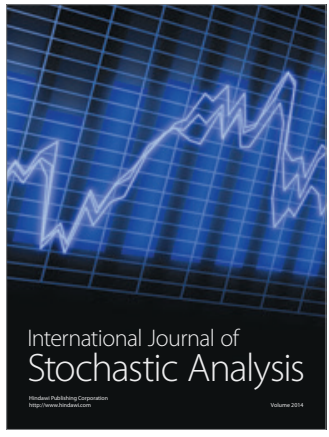

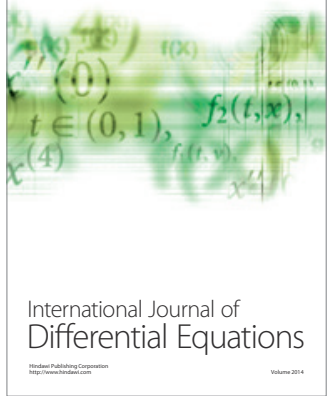
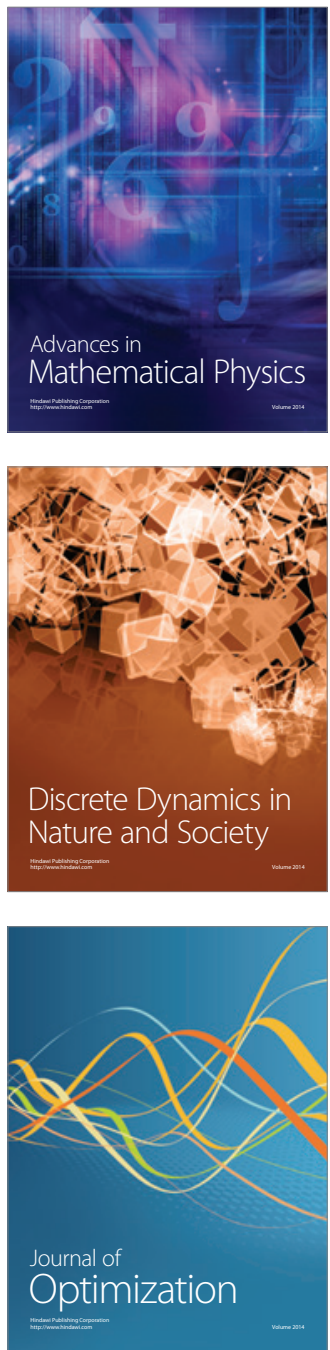